Vol. LXVI 2015

\title{
RIGHTPOLLEX: FROM PATENT TO STARTUP
}

\author{
LEBA Monica \\ Computer and Electrical Engineering Department, University of Petrosani, Petrosani, Romania, \\ monicaleba@yahoo.com
}

\section{IONICA Andreea Cristina}

Department of Management, University of Petrosani, Petrosani, Romania, andreeaionica2000@yahoo.com

\author{
DOBRA Remus \\ Computer and Electrical Engineering Department, University of Petrosani, Petrosani, Romania, \\ dobraremus@yahoo.com
}

\begin{abstract}
RightPollex is an innovative product patented and developed by a multidisciplinary team from the University of Petrosani. The paper presents not only the idea and implementation possibilities of this patent, but also the current stage on the path towards the development of startups, an initiative of our university together with a private investor. The result of this initiative is JV Sensor Ventures that supports several startups.
\end{abstract}

Key words: innovation, biometric, research

\section{Introduction}

Paul Graham says that "A startup is a company designed to grow fast. Being newly founded does not in itself make a company a startup. Nor is it necessary for a startup to work on technology, or take venture funding, or have some sort of "exit." The only essential thing is growth. Everything else we associate with startups follows from growth." Graham added that an entrepreneur starting a startup is committing to solve a harder type of problem than ordinary businesses do. "You're committing to search for one of the rare ideas that generates rapid growth." [1]

Getting a business off the ground and into profitability, going from "idea to product" and "team to company” typically involves a number of stages, as presented in figure 1.

Figure 1: Startup typical life-cycle

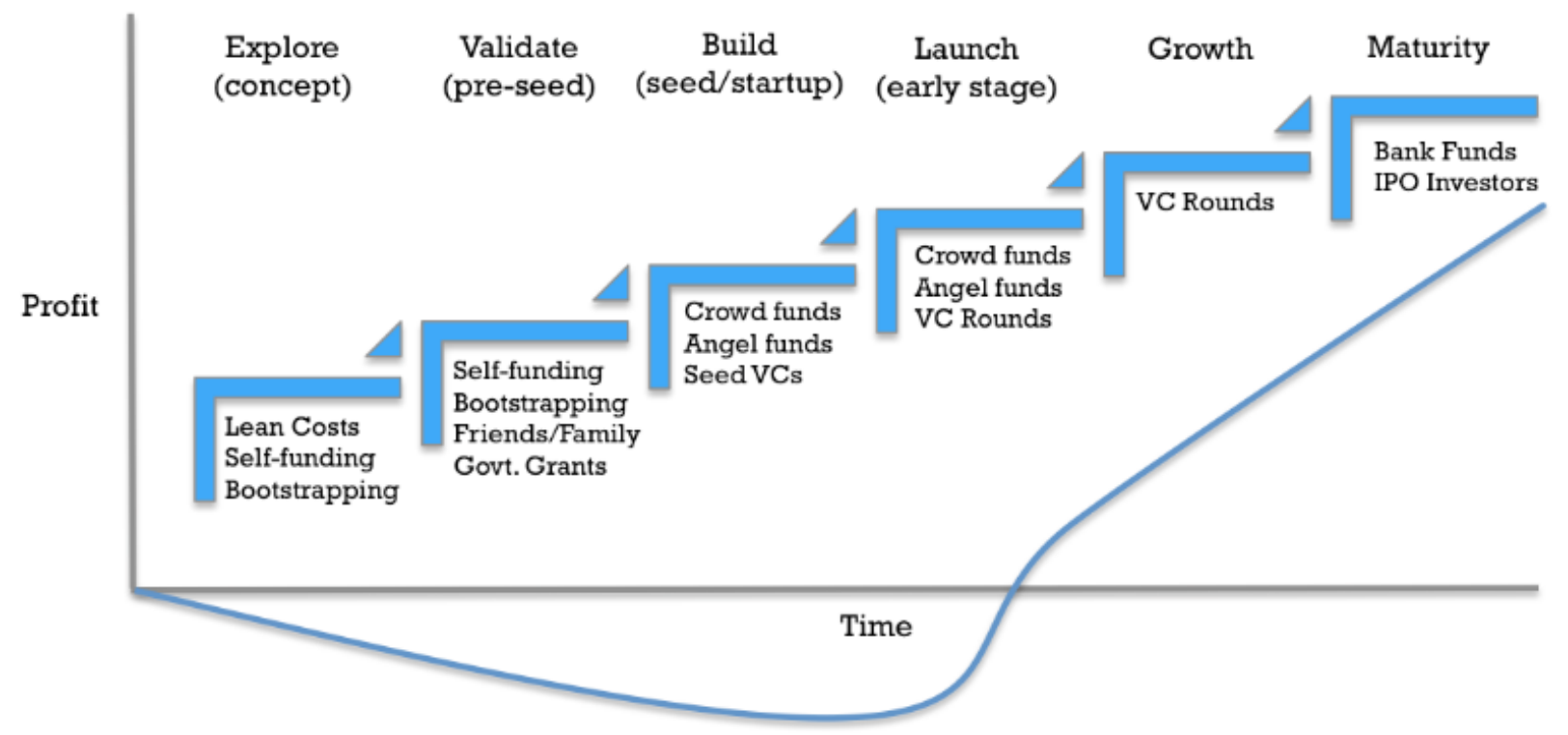

(source: https://albertobalatti.files.wordpress.com/2014/08/maltaway balattiboardmember_startupfunding-lifecycle-venture-capital.png) 
Businesses can obviously fail too, and this is most likely to occur in the early stages, when the company is funded by seed capital, angel investors and/or 'friends, family and fools' (FFF), and is yet to generate significant revenue.

Assuming the business survives, various early-stage and later-stage financing rounds may then be negotiated, allowing the products to mature and penetrate their markets. Many promising companies are acquired during this period; if they're not, the next major milestone is often the IPO (Initial Public Offering). Not all IPOs go as planned, however, and many startups choose to remain in private hands if they have the means to finance their growth plans. Occasionally, public companies return to private ownership. [2]

\section{Universities and startups}

Startups need ambitious and smart people. The best places for these resources are, obviously, the universities. In Universities study students from multidisciplinary fields. These students can easily interact with each other, in order to form up a well-structured team ready to get involved in early stage startups. Most accelerators want to see highly-motivated and hard-working startup teams that bring a diversity of skills, knowledge and experience, says Christine Tsai, partner at 500 startups. [3]

\section{Figure 2: Startups fields}

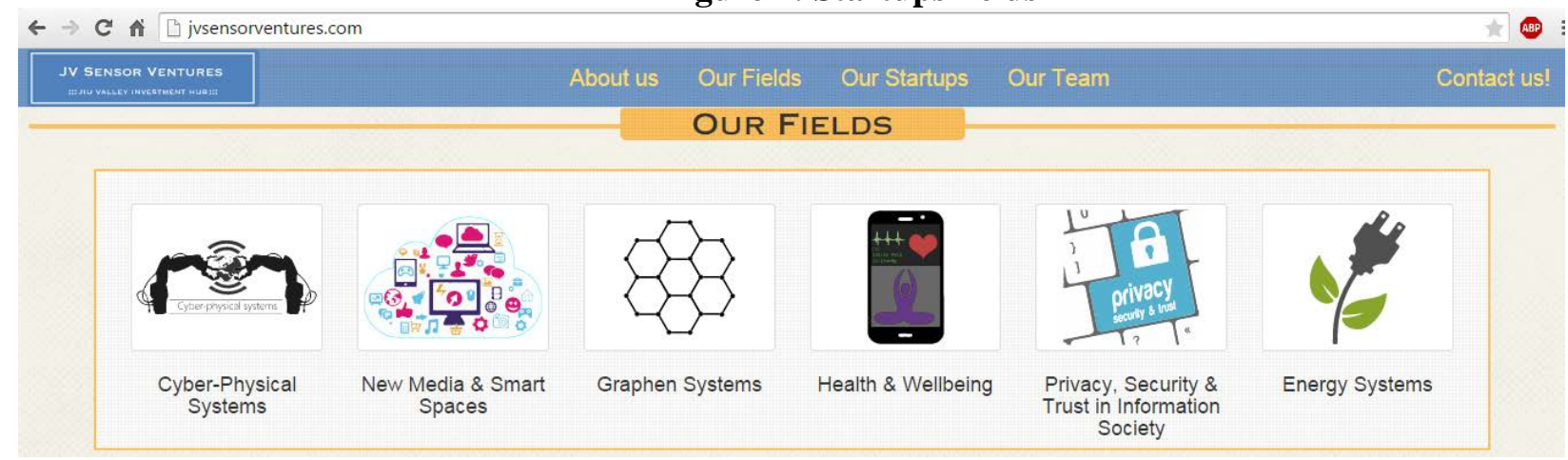

Figure 3: Startups

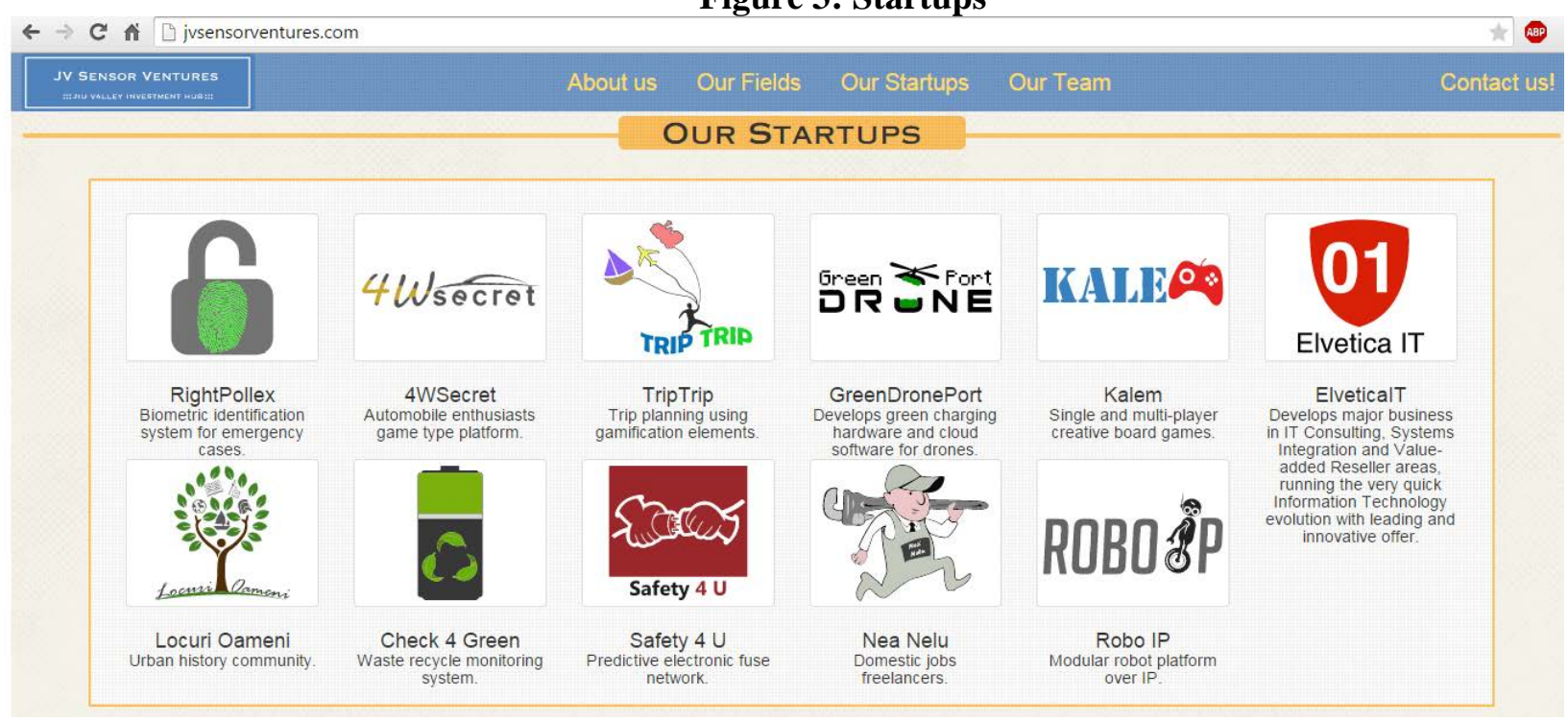

The Global Entrepreneurship Monitor Report shows that most of the entrepreneurs from the early stage startups are very young (18-25 years old), mostly university students, thus being the largest group of present worldwide entrepreneurs. This is probably due to their higher risk tolerance, tendency to experiment more and to smoothly deal with both the success and failure of an early stage startup. activity.

Prior research suggests four macro-level explanations for university implications in start-up

- The presence of venture capital close to the university area ensures the necessary resources for start-ups generation.

- The industry-funded research developed in universities lead to market-oriented products that can be the subject of a start-up. 
- The patents developed as a result of university research can also be the source for new start-ups.

- The adoption of support policies for entrepreneurial activity in universities provides the framework for start-ups outset. [4]

At the University of Petrosani, we started an initiative called JV Sensor Ventures (www.jvsensorventures.com) in order to support startups in the fields presented in figure 2.

Till now the featured startups from figure 3 are in various early stages. Many of these are the result of students' internship program [5].

From these startups we will present next RightPollex, that is the subject of a national OSIM patent. [6] The patent is related to a particular application of RightPollex for medical emergencies.

\section{RightPollex}

The development of this innovative product follows the well-known lifecycle, consisting in requirements capture, system design, development and implementation of the system (hardware and software), testing. The research methodology was based on the collaboration between specialists from different fields, like computer engineering, electronics, quality management and potential users, and led to the objective achievement, the biometric identification system first for emergency medical situations and subsequent, by refining the requirements and enlarging the target group, for lost persons identification, data protection and travel or life insurance contact person.

This developed product is based on a method that eliminates the classical methods insufficiencies by optimizing the time response, facilitating access and by ensuring an increased security regarding the primary information for any of the above situations. The approach is developed for storage of information based on biometric identification by means of fingerprint sensor.

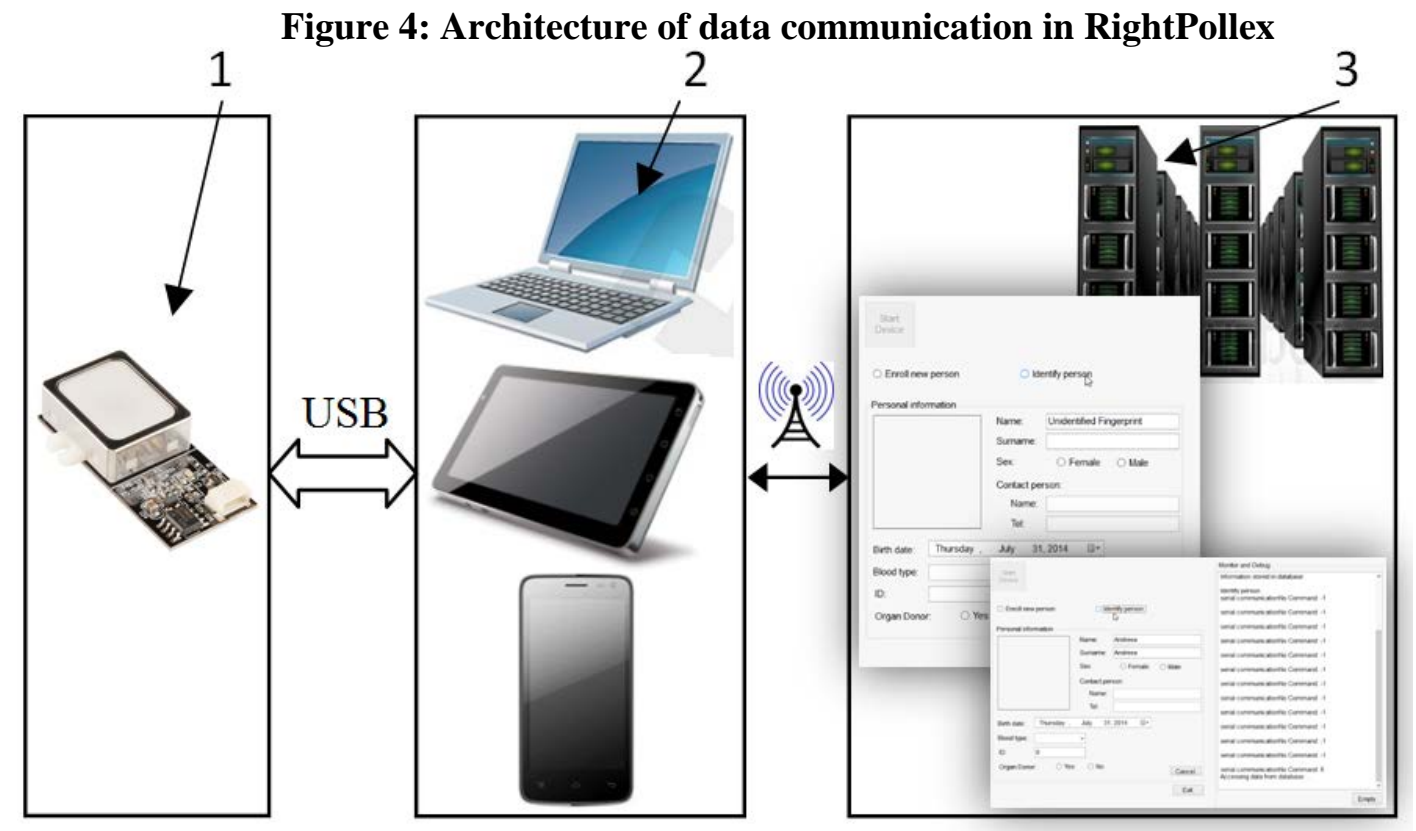

The identification is made using a biometric digital interface, which takes over information regarding the fingerprint using a fingerprint sensor and transmit them to the microprocessor, via a serial protocol. Loading persons' data is made in specialized offices that offer this service and the reading part take place in the any location related to the service, using a classical PC or laptop (2), connected to the digital biometric system (1), via either a USB cable, or using wireless or Bluetooth protocol. Data transmission to the central system, for storing data in the central database, located on the server (3), is done through secured internet protocol.

Figure 5 shows the software and hardware prototype interfaces for this project 
Figure 5: RightPollex hardware and software interfaces

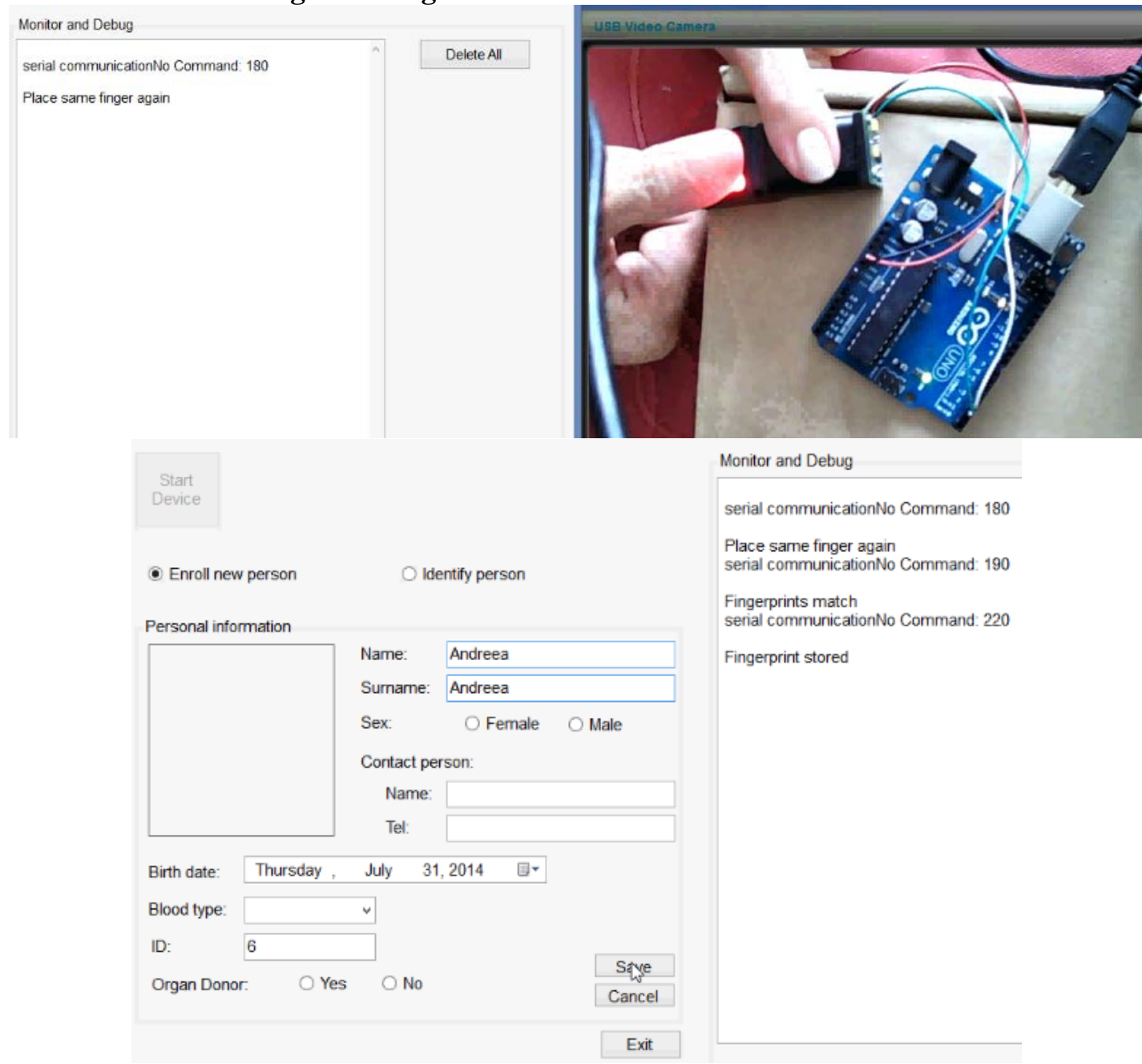

\section{Conclusions}

This paper presents the path from patented idea to development of a MVP (Minimum Viable Product) as the basis for the early stage of a startup. Even if we are in the beginning, early stage, we develop activities scheduled to increase our startups and initiate new ones.

University - business environment partnership in the development of startups allows eliminating a significant percentage of unviable ideas by using mainly patented ideas validated by research conducted in the university, ideas used as such or adapted for application in other areas.

\section{References}

- Graham, P. Startup Equals Growth, in Graham's Essays on entrepreneurship (2012)

- http://www.zdnet.com/article/understanding-the-enterprise-startup-lifecycle/

- http://www.wired.com/2014/02/university-ideal-startup-platform/

- Di Gregorio, D., Shane, S. Why do some universities generate more start-ups than others?, Research Policy, 32, pp. 209-227(2003)

- Cioca, M., Ghete, A.I., Cioca, L.I., Gîfu, D., Machine Learning and Creative Methods used to Classify Customers in a CRM Systems, Applied Mechanics and Materials, Vol 371, pp. 769-773, Aug. 2013.

- Leba, M., Dobra, R., Ionica, A., Method of Storing Relevant Medical Information Based on Biometric Identification, O.S.I.M. Romanian Patent No. A 201400167 / 27.02.2014 